\title{
Blood Stain with Hammer Imprint Shown in Crime Scene
}

\author{
Samir Kumar Bandyopadhyay, Nabanita Basu \\ Department of Computer Science \& Engineering, University of Calcutta, Kolkata, India \\ Email: skb1@vsnl.com, nabs.basu@gmail.com
}

Received 5 April 2015; accepted 20 April 2015; published 24 April 2015

Copyright (C) 2015 by authors and OALib.

This work is licensed under the Creative Commons Attribution International License (CC BY).

http://creativecommons.org/licenses/by/4.0/

(c) (i) Open Access

\begin{abstract}
Like most other areas of Forensic Science, bloodstain pattern evidence interpretation is characterized by the overlap from various other fields of science such as physics, computer science, medical science etc. For example, fluid mechanics particularly explains the forces that lead to the formation of a particular bloodstain pattern. Forensic Medical practitioners particularly work towards drawing the correlation between the bloodstain patterns formed and the wound formed on the body or head of the victim concerned. The paper studied hammer transfer stains in particular because of the easy availability and usability of hammer round the world. Also we studied effect of stain pattern in the crime scene. The authors are of the view that of the different types of bloodstain patterns, the most common stain patterns visible at the crime scene, particularly in the case where the victim is found to suffer blunt force injuries, are saturation, impact, cast off and transfer stain patterns.
\end{abstract}

\section{Keywords}

Bloodstain Pattern Analysis, Transfer Stain, Hammer, Imprint in Blood, Porcine Blood, Crime Scene Documentation, Crime Scene Reconstruction, Interpretation, Tool, Murder Weapon

Subject Areas: Computer Engineering

\section{Introduction}

Computer scientists have worked out methods to automatize the process of calculation of the area of origin for a bloodstain pattern. The manual Stringing method that was used for calculation of the area of origin (in 3D) or the point of convergence (in 2D) for a bloodstain impact spatter often led to contamination of relevant evidence at a crime scene. Computer based automation of this process help analysts get over such drawbacks.

While Mathematical models developed have helped investigators make a near accurate estimation of the area 
of origin, computer science helps at automatizing the mathematical estimation of the area of origin in a 3 dimensional space with reduced human effort. Such evidence is useful in the court of law in order to draw evidentially supported conclusions about the murder weapon that might have been used, the number of blows struck, the position of the perpetrator, victim and bystander (if any) etc.

Bloodstain evidence not only helps sequence events in a crime scene, it also helps prove or disprove eyewitness testimony, suspect statements etc. As per the UCR program conducted by the FBI, Violent Crime primarily comprises of murder and non-negligent manslaughter, forcible rape, robbery and aggravated assault.

The UCR program defines Violent Crime as those offenses which involve force or threat of force. In coherence with the crime definitions put forward by the UCR program, the National Crime Record Bureau, India, categorizes violent crime under the following heads-Murder, Attempt to Commit Murder, Culpable Homicide not amounting to murder, Rape, Kidnapping and Abduction, Dacoity, Preparation and assembly for dacoity, Robbery, Riots, Arson and Dowry Deaths.

\section{Review Works}

The Oxford Dictionary defines "Crime" as "an action or omission which constitutes an offence and is punishable by law". The Uniform Crime Reporting program conducted by the Federal Bureau of Investigation (FBI) divides offences particularly into 3 broad categories based on the seriousness of the crime. They are-Part I offences, Part II offences and Other Offences. Part I offences as the FBI records are serious crimes that occur with regularity in all areas of the country and are likely to be reported to the police. Part I offenses include Criminal homicide, forcible rape, aggravated assault, burglary (breaking or entering), Larceny-theft (except motor vehicle theft), motor vehicle theft, arson. Part II offences include, other assaults (simple), Forgery and Counterfeiting, Fraud, Embezzlement, Stolen property: buying, receiving, possessing, Vandalism, Weapons: carrying, possessing etc., Prostitution and Commercialized vice, Sex offenses (except forcible rape, prostitution, and commercialized vice), Drug abuse violations, Gambling, Offenses against the family and children, Driving under the influence of an intoxicant, Liquor laws, Drunkenness, Disorderly conduct, Vagrancy. Other offenses include Suspicion, Violations by juveniles (under the age of 18) of local curfew or loitering ordinances, runaways by juveniles (under the age of 18) taken into protective custody under the provisions of local statutes.

As per the UCR program conducted by the FBI, Violent Crime primarily comprises of murder and non-negligent manslaughter, forcible rape, robbery and aggravated assault. The UCR program defines Violent Crime as those offenses which involve force or threat of force. In coherence with the crime definitions put forward by the UCR program, the National Crime Record Bureau, India, categorizes violent crime under the following headsMurder, Attempt to Commit Murder, Culpable Homicide not amounting to murder, Rape, Kidnapping and Abduction, Dacoity, Preparation and assembly for dacoity, Robbery, Riots, Arson and Dowry Deaths. These crimes are under most circumstances accompanied by bloodletting events. It is this subset of crimes that we intend to work on this particular project. Evidence is useful in the court of law in order to draw evidentially supported conclusions about the murder weapon that might have been used, the number of blows struck, the position of the perpetrator, victim and bystander (if any) etc. Bloodstain evidence not only helps sequence events in a crime scene, it also helps prove or disprove eyewitness testimony, suspect statements etc.

It is possible to develop a tool that is efficient at analyzing and probabilistically predicting a particular sort of transfer stain. However, development of a dataset consisting of a large variety of weapon transfer stains formed by different angle of inclination of tool drop, dimension of tool edge, fall height, velocity of hit etc. stands integral.

In 2011, the Federal Bureau of Investigation (FBI) reported that the number of individuals killed (496) by blunt objects which might include a hammer, golf stick, a coconut shell (ripe, unripe), a wooden box, a candlestick/stand etc. by far outnumbered the number of individuals killed by rifle shot [1]. It's not just 2011 recorded such figures, since 2005 to 2011, the number of individuals who have been killed by a blunt object hit have by far outnumbered the number of individuals killed by a rifle shot [1]. "The bloodstain resulting from contact between a blood bearing surface and another surface" is defined as Transfer stain by the International Association of Bloodstain Pattern Analysts (IABPA) [2]. Identification of a murder weapon can be done by analyzing weapon transfer stains (if any) together with other circumstantial evidence at a crime scene. Hand transfer stains, shoe transfer stains as also weapon transfer stains left at a crime scene play an integral role in the reconstruction of the crime scene, hence proper documentation of such stains is mandatory (Figure 1). 


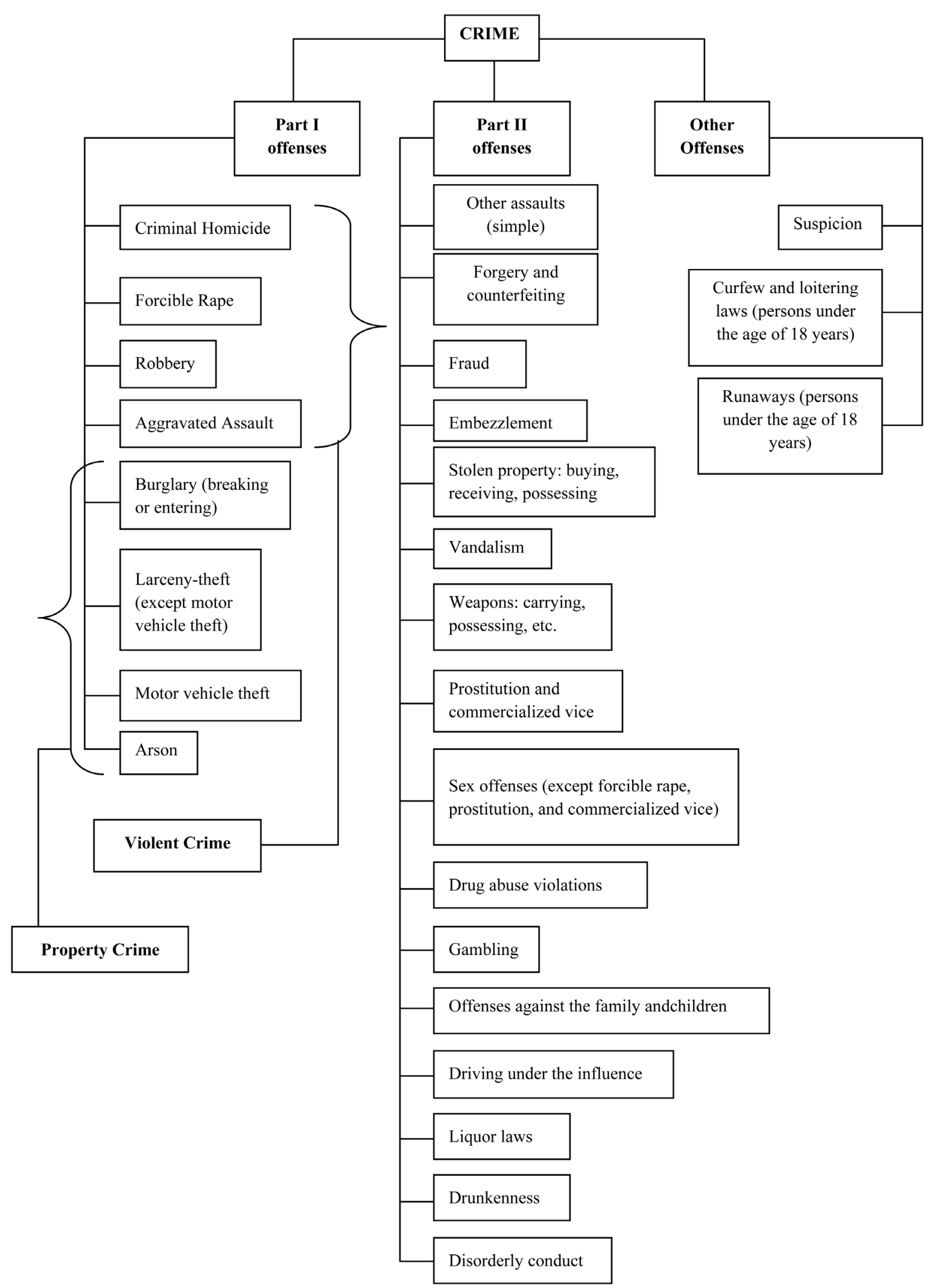

Figure 1. A crime classification chart developed by the united crime reporting program conducted by the federal bureau of investigation. 
In this regard, the case of the ex-FBI agent in 2010 is particularly relevant. On December 13, the Sun News reported how the imprint of hammer in the blood pool could influence the court's understanding of the case as a case of successful attempted murder or a murder committed in self-defense [3].

The “Crime in India Report 2013” published by the National Crime Record Bureau, suggests that there has been a subsequent yet persistent increase in violent crime rate over the last 20 years. The ever increasing number of unsolved criminal cases within the Indian juridical setting makes this project particularly timely in the present scenario.

Now that the reader/s has a clear idea of which particular subsection of crime we particularly intend to deal with, it would not be out of place to provide a graphical overview of how criminal offense is dealt with within the Indian juridical setting. Figure 2 summarizes the Juridical setting relevant to trial of a criminal complaint within the Indian juridical system.

\section{Experiments and Results}

The authors used porcine blood for the experiments because porcine blood is quite similar to human blood. Blood was legally procured from Kolkata Municipal Pig Slaughter House, Tangra Kolkata, India. Given that fresh blood coagulates over time, $1100 \mathrm{IU}$ of Heparin Injection was added to fresh pig blood to preserve the colloidal consistency of blood. It might be interesting to mention that adding anticoagulant does not alter the viscosity and specificity of the Non-Newtonian fluid, blood.

At the very onset, a hollow coconut with a hair wig (refer Figure 3) was used to simulate the head hit event in a crime scene. The authors particularly attempted to reconstruct the event of back head hit in a crime scene. The

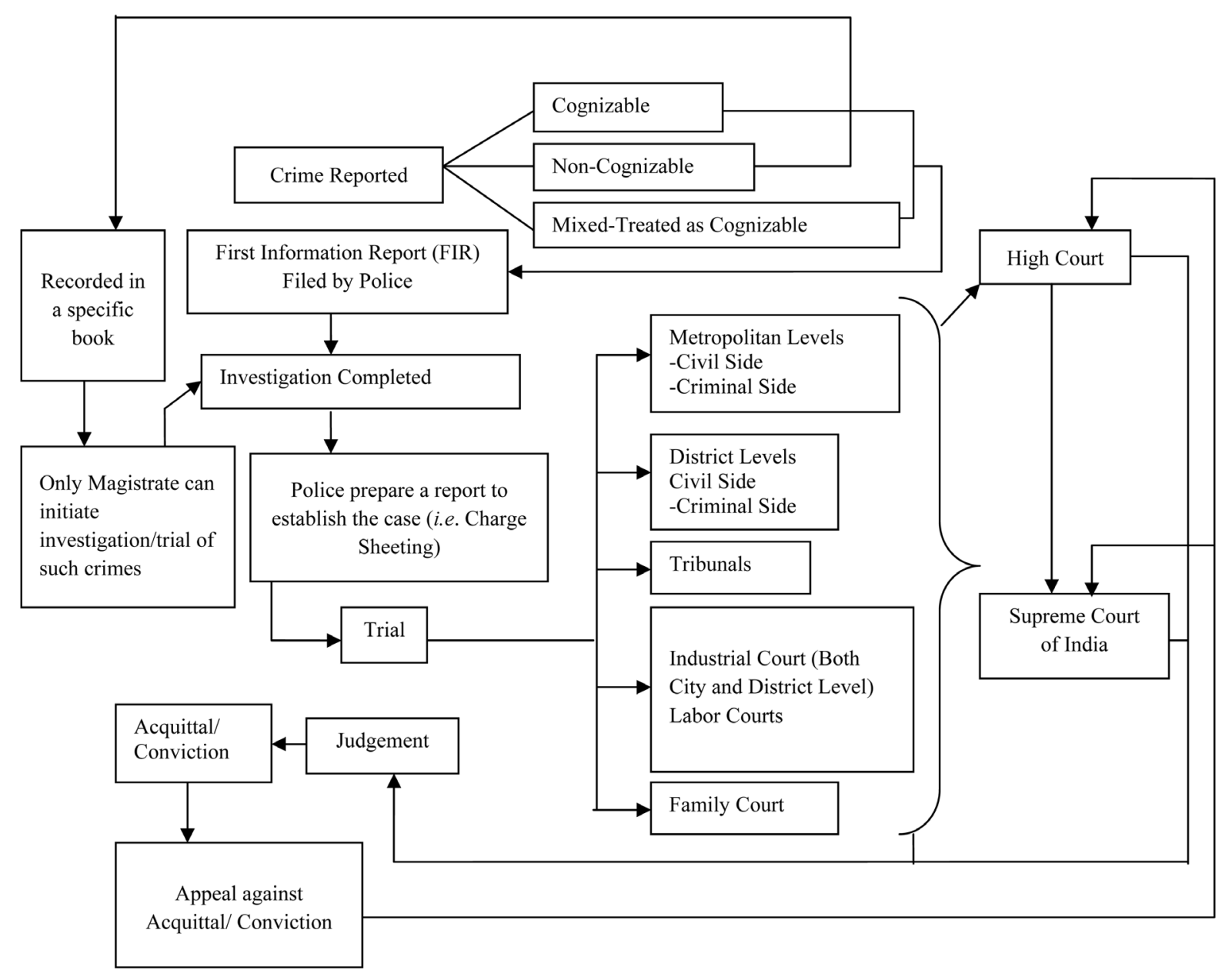

Figure 2. Flow chart describing the trial of a criminal complaint within the Indian juridical setting. 
hair wig was soaked in 20 cc. of pig blood in order to create the bloody hammer transfer stains one might expect to see after head hit. By way of study of the juridical proceedings for several criminal cases and by conducting a brief survey of the available hammers at the local market, the authors prepared a list of 6 different hammers to be used in the study.

The experiment was performed in 2 phases. In the first phase the coconut shell was hit with each hammer consecutively for 10 times and then each hammer was dropped from a height of $40 \mathrm{cms}, 60 \mathrm{cms}$ and $80 \mathrm{cms}$ respectively. In order to minimize or control propertydamage the hammer was dropped on a paper sheet (A3 size) placed on a thermocol sheet (refer Figure 4).

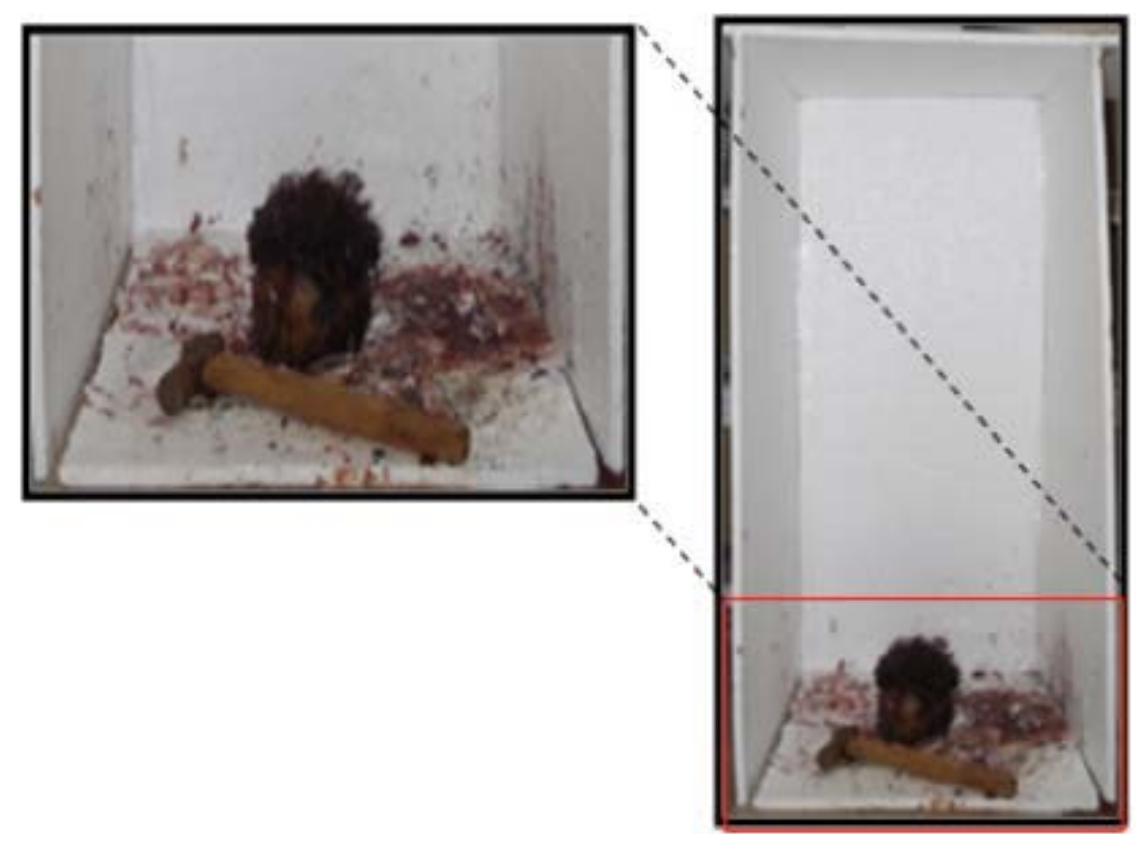

Figure 3. Experimental Setup replicating the event of a head hit. As the authors were not inclined towards recording the stains (particularly cast off and impact spatter patterns) formed on the walls and ceilings for a particular height of the victim, perpetrator, number of hits made by the perpetrator, hence this setup was constructed.

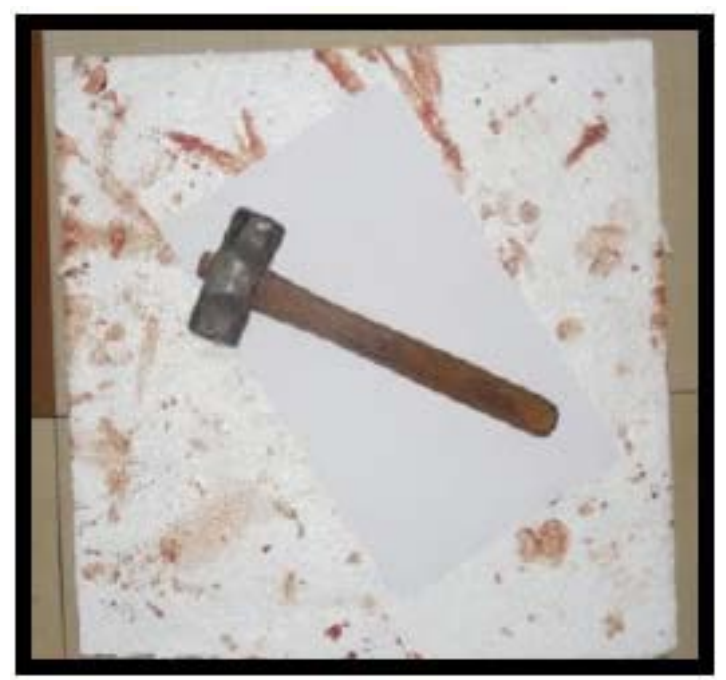

Figure 4. Thermocol sheet placed on the floor to avoid damage of the floor tiles. Paper sheet is placed on the thermocol sheet and hammer is dropped on the paper sheet by measuring the fall height from the top of the thermocol sheet. 
The fall height was measured from the top of the thermocol sheet. In the next part of the experiment, each hammer was again used for 10 head hits, then dropped in a $30 \mathrm{cc}$. blood pool, picked up and again made to fall from a height of $40 \mathrm{cms}, 60 \mathrm{cms}$, and $80 \mathrm{cms}$ respectively.

In the second phase, the bloody edge impression of each hammer was taken after 10 head hits. Two impressions of each edge were recorded in the course of the experiment. In the first instance, the hammer was simply placed on a plain/smooth non-absorbent surface (paper) with the bloody edge being the only contact point between the surface and the hammer for a brief period of 5 secs. In the second part of the experiment, after 10 head hits the paper surface was struck with the bloody edge of the hammer at a particular velocity. The paper surface wasn't hit with an extremely large force as because a full force hit was found to rupture the paper surface (refer Figure 5).

By way of experimentation the authors arrived at the conclusion that the angle of inclination of the hammer at fall as also the orientation of the hammer at which it starts falling decides which part of the hammer would touch the target surface first. Again, certain parts of the hammer may not even fall in the blood pool or might have very few blood molecules attached to the surface depending on the volume of blood in the blood pool in comparison with the volume of the hammer. Hence even if a hammer drops in a blood pool after 10 head hits and is picked up from the pool and allowed to fall bloody face down from a height of 40,60 and $80 \mathrm{cms}$ respectively, then a complete bloody transfer stain of the hammer face might not be formed on a plain/smooth, non-absorbent, non-porous surface (refer Figure 6).

To be more precise, when the target substance is softer and the initial impact force exceeds the normal force, cracks and dents are formed. Hence blood stain transfer pattern is particularly affected by the variation in the quantity of blood attached to the edge, initial impact velocity, and relative hardness/softness of the target surface material. When the same amount of blood was allowed to drop from a height of $10 \mathrm{cms}$ and a height of $100 \mathrm{cms}$, a difference in the size/diameter of the blood drop was recorded. The greater the force of impact, the more one could expect the blood attached on the surface of the object to spatter and hence form satellites as because the force is more likely to exceed the surface tension of blood (refer Figure 7(a) and Figure 7(b)).

When it comes to substances that are harder than paper and again softer than the material with which the hammer head is built (cast iron in this case) such as certain flooring marble slab, scratches are formed when hit by the hammer with a certain initial impact velocity. For larger initial impact velocities cracks are formed (refer Figure 8).

Of the different types of bloodstains patterns such as drip trails, impact patterns, expiration stains, blood flow pattern, saturation stains etc., the authors were particularly interested in the review of work done with particular focus on the impact patterns, expiratory bloodstain patterns and transfer stain patterns on fabrics. The images are shown below (Figure 9 and Figure 10).

Paper is much softer than iron (the material the hammer head is made up of) hence when hit with a certain amount of Initial impact velocity that is not large it sags with crease formation on the surrounding. For an even larger initial Impact velocity it tears off (refer Figure 11).

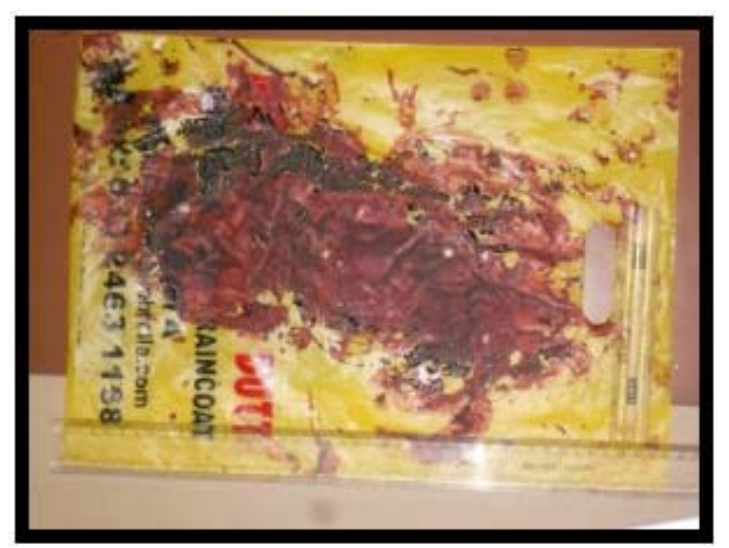

Figure 5. Dried up 30 cc blood pool created on a plastic sheet. The blood pool was not created on paper as the paper surface would cringe on the drying of the $30 \mathrm{cc}(\mathrm{ml})$ blood pool. 

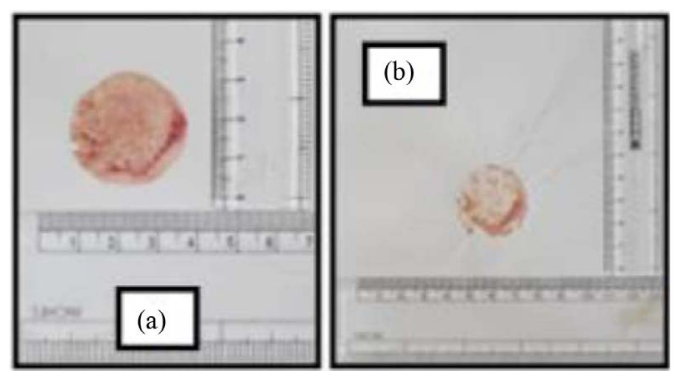

Figure 6. A comparative image of the transfer stains cast by the same edge of the ball peen hammer. (a) Represents stain ball pen hammer type 1; (b) Represents stain ball pen hammer type 2 .

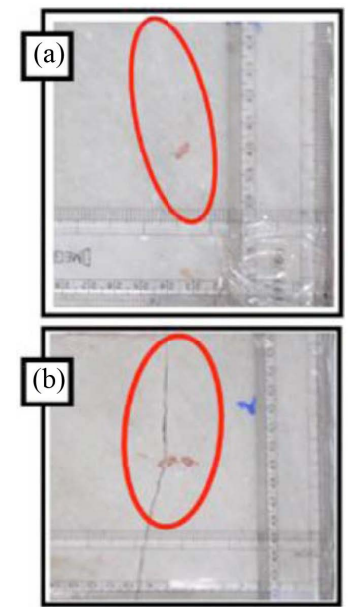

Figure 7. (a) Marble slab used for flooring when hit with a particular velocity by a bloody ball peen hammer edge after10 consecutive head hits results in scratch formation; (b) Marble slab hit with higher initial impact velocity by the same edge of the ball peen hammer after 10 consecutive head hits results in formation of a crack.

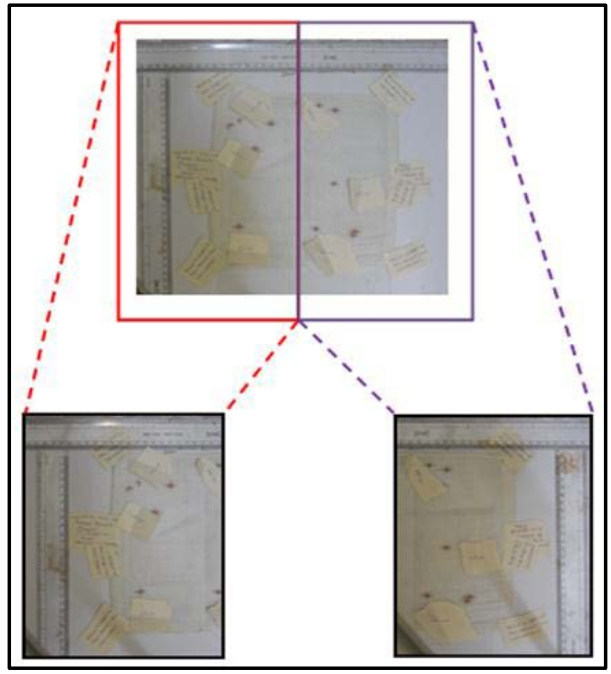

Figure 8. The overall view of the cotton cloth on which the stains were taken. The left side contains stains created with fresh pig. The right half of the cloth contains bloodstains created from pig blood thoroughly mixed with anticoagulant. 


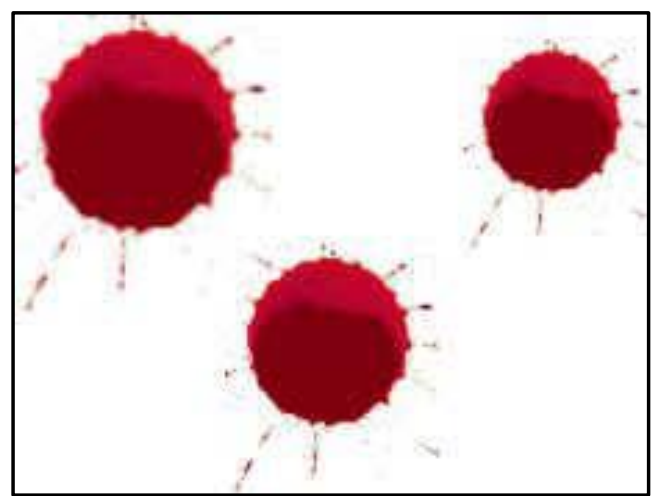

Figure 9. Drip stains/patterns (caused by the force of gravity only).

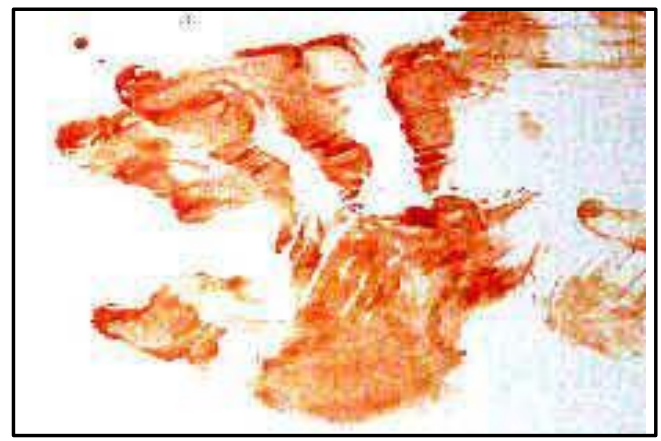

Figure 10. Transfer stain/patterns in fabrics.

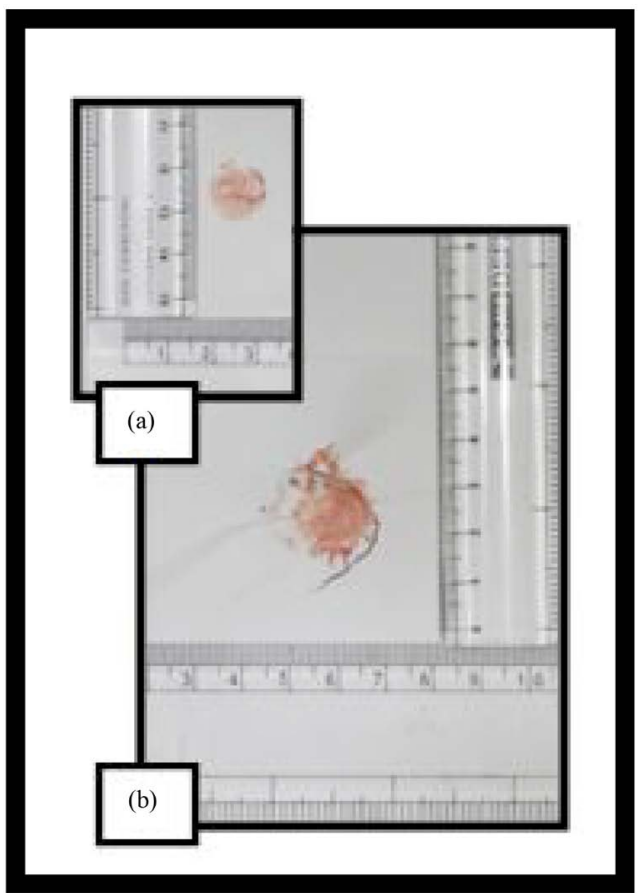

Figure 11. (a) Stain formed when round edge of cross peen and straight hammer was used for 10 head hits and then placed on plain, non-absorbent paper; (b) Stain formed when the same edge after 10 head hits was used to hit plain, non-absorbent paper surface with a comparatively larger initial impact velocity thereby leading to rupture of paper surface. 


\section{Conclusion}

A hammer imprint or transfer stain in a crime scene does not necessarily on a standalone basis prove that the hammer has been used as a murder weapon in the crime scene. Again, based on the mechanism in which the transfer stains were created, the transfer stains can be markedly different for the same object in question. Given the large variation in the types of hammers, blunt objects and also the large variation in the transfer stains, depending on quantity of blood, temperature, dimensions of the object, it is impossible to make predictions about the object that has left the stain, based on transfer stains alone in most cases. It is even more difficult to analyze superimposed stains. So the paper concludes with the statement that transfer stains or tool imprints in blood should be studied in coherence or in light of other circumstantial evidence in order to be used in the process of sequencing of events in a crime scene and thereby for crime scene reconstruction.

\section{References}

[1] Washington CBS Local (2013) FBI: Hammers, Clubs Kill More People than Rifles, Shotguns CBS DC. http://washington.cbslocal.com/2013/01/03/fbi-hammers-clubs-kill-more-people-than-rifles-shotguns/

[2] Scientific Working Group on Bloodstain Pattern Analysis (2009) FBI—Standards and Guidelines—Scientific Working Group on Bloodstain Pattern Analysis: Recommended Terminology. http://www.fbi.gov/about-us/lab/forensic-science-communications/fsc/april2009/standards/2009_04_standards01.htm

[3] Toplikar, D. (2010) Blood Stain with Hammer Imprint Shown in Ex-FBI Agent’s Murder Trial_Las Vegas Sun News. http://www.lasvegassun.com/news/2010/dec/13/blood-stain-showed-imprint-hammer-says-analyst-ex-/ 